\section{Perspectivist tradition leads men of vision}

\author{
J. D. Mollon
}

Theories of Vision from Al-Kindi to Kepler. By D. C. Lindberg. Pp. xii+ 324. (University of Chicago: Chicago and London, 1976.) £13.60.

IN laboratories and coffee-rooms it is countless times debated whether a knowledge of the literature allows the scientist to stand on the shoulders of his predecessors or merely bestows on him a damnosa hereditas, fatally constraining his thought. The literature man scorns the rediscoveries and the omitted controls of his unread colleague: the latter argues that it is of ten faster to do the experiment than to find the answer in the literature and points to the low publication rate of the literature man.

Two of the greatest contributors to our understanding of visual perception, Thomas Young and Hermann Helmholtz, were literature men of enormous erudition whose systematisations too easily conceal from us the achievements of the eighteenth century. In his book, D. C. Lindberg argues that a third outstanding innovator in the theory of vision, Kepler, was not a revolutionary working in a vacuum but rather represents the culmination of the perspectivist tradition that extends back to the Islamic writers of the ninth and tenth centuries. He shows that AlKindi first made explicit the principle that luminous rays issue in every direction from every point on the surface of a luminous body and that Alhazen set the problem, that of establishing a one-to-one correspondence between points in the visual field and points on some plane in the eye. The preKeplerian solution was to assign an especial potency to those rays that were perpendicular to the surface of the cornea, that is, to those making up the visual cone, with its base on the object of vision and its apex at the centre of curvature of the cornea. (Lindberg does not notice that this theory is lent some truth by the Stiles-Crawford effect, the directional selectivity of the photoreceptors that favours rays normal to the retina). Kepler, equipped with the improved anatomy of Felix
Platter and with his own understanding of the focusing properties of transparent spheres, was able to offer the correct solution, that the crystalline humour is not itself the seat of vision but in combination with the cornea serves to form an inverted image on the retina. But, Lindberg argues, the perspectivist tradition gave Kepler his problem, his facts, his methodological rules and his criteria of success. In this conclusion Lindberg explicitly opposes the standard view that Kepler transformed visual theory by mechanising it: "Kepler presented a new solution (but not a new kind of solution) to a mediaeval problem, defined some six hundred years earlier by Alhazen".

Lindberg himself is clearly a literature man by temperament. His impressive grasp of the primary Latin texts is complemented by a very wide knowledge of the academic literature: his book has over 1,000 footnotes to secondary sources. So it is understandable that he is unimpressed by Leonardo's contribution to visual theory. Leonardo was avowedly not a literature man and himself wrote: "If indeed $I$ have no power to quote from authors as they have, it is a far bigger and more worthy thing to read by the light of experience, which is the instructress of their masters. They strut about puffed up and pompous, decked out and adorned not with their own labours but by those of others, and they will not allow me my own". Lindberg believes that Leonardo had read Pecham and Witelo but that his knowledge of the optical tradition was imperfect. Usually Leonardo did not work with Al-Kindi's principle of punctiform analysis but rather thought of the species, or image, of an object as radiating holistically. His understanding of the formation of images by reflection and refraction was limited. It is particularly curious that this skilful anatomist was so weak in ocular anatomy: he confounded the vitreous and the crystalline and supposed that the eye consisted of two concentric spheres. By reading any of the mediaeval perspectivists he would have been furnished with a more sophisticated account. Lindberg is mistaken, however, in admonishing Leonardo for claiming that the apparent size of objects increases with the size of the pupil: there is a clear basis for this observation in the phenomenon of irradiation. Leonardo's explanation is another matter, but it is noteworthy that his claim about the effect of pupillary size is contained in the same manuscript ( $F$ of the Library of the Institut de France) as his observation that a uniform iron rod heated only in part of its length will appear considerably larger in its heated part. The latter phenomenon is primarily a consequence of irradiation.

The theory of optics and vision was central to mediaeval philosophy and provided a link between physics, medicine and theology. Optics was, for example, fundamental in Bacon's planned synthesis of all human knowledge. Lindberg's book should therefore be of interest to mediaeval historians in general. He draws attention, for example, to the neglect of the history of the translations from Greek and Arabic to Latin in the twelth century: almost nothing is known of the purposes and motivation of the translators, of the selection of works or of the mechanics of translation; and towards the further understanding of this crucial movement, Lindberg provides a detailed Appendix on the translation of optical works.

The book is illustrated with many diagrams of the eye drawn from ancient and mediaeval authors. Man's idealised representations of his own visual organ serve nicely to illustrate how his perception is influenced by his conceptual framework. Perhaps we can never accurately perceive a biological mechanism until we have constructed the artefact that will serve as a model: we must have lenses before we can perceive the eye as an image-forming device and computers before we can perceive the brain as an informationprocessing machine. What is regrettable is that Lindberg nowhere includes an accurate modern diagram of the eye, an inclusion that would have been invaluable to the general reader trying to follow mediaeval discussions of whether there are four tunics or seven, three humours or two.

To reduce his material to manageable proportions, Lindberg omits discussion of theories of the physiology and psychology of vision. To some extent this exclusion is artificial, for it is clear that many of Kepler's predecessors (including Leonardo) were held back from the correct solution by explicit reluctance to entertain an inversion of the image; and Kepler himself acknowledged that he "dutifully tortured" himself "in order to show that the cones intersecting when they pass through the aperture of the uvea intersect again behind the crystalline, in the middle of the vitreous humour, so that another inversion is produced." But he protested that geometry allowed no escape from an inverted image and thereby bequeathed to his own successors a new and peculiarly vexatious problem.

J. D. Mollon is Lecturer in Experimental Philosophy at the University of Edinburgh, UK. 